\title{
Perception and Understanding of Greek Dentists on Periodontal Regenerative Procedures: A Questionnaire Based Study
}

\author{
Violesti AK ${ }^{1}$, Malamoudi G ${ }^{1}$, Chatzopoulou $\mathrm{D}^{2}$, Sakellari $\mathrm{D}^{1 *}$ and Gillam DG ${ }^{2}$ \\ ${ }^{1}$ Department of Preventive Dentistry, Periodontology and Implant Biology, School of Dentistry, Aristotle University of Thessaloniki, Thessaloniki, Greece \\ ${ }^{2}$ Institute of Dentistry, Barts and the London School of Medicine and Dentistry, Queen Mary University London, London E1 2AD, UK
}

${ }^{\star}$ Corresponding author: Dimitra Sakellari DDS, PhD, Department of Preventive Dentistry, Periodontology and Implant Biology, School of Dentistry, Aristotle University of Thessaloniki, 54636, Greece; E-mail: dimisak@dent.auth.gr

Received: December 08, 2020; Accepted: December 15, 2020; Published: December 17, 2020

\begin{abstract}
Objectives: The aim of this cross-sectional questionnaire study was to evaluate the perception and preferences of Greek dentists who either specialised in or had an interest in periodontal regenerative procedures and to compare the results with corresponding findings from two previous studies from different countries.

Materials and methods: The questionnaire was divided in two main sections and included multiple choice and/or open/closed questions. The first section consisted of six questions and was designed to collect demographic data of the sample and the second section, consisting of 15 questions, included general questions regarding periodontal regeneration procedures and questions based on specific clinical cases. 200 questionnaires were distributed at selected venues in Greece by the investigators. The participants were given one month to complete and return to the questionnaires to the School of Dentistry in Thessaloniki.
\end{abstract}

Statistical analysis: Data management and analysis was performed using both Microsoft Excel 2007® (Microsoft Corporation, Reading, UK) and SPSS® version 22.0 software (IBM United Kingdom Ltd, Portsmouth, UK). Frequencies and associations between the demographic profiles of the participants were evaluated and presented in the form of frequency tables, charts, and figures.

Results: 104 questionnaires (67 males, 37 females: mean age 43.2 years [ \pm 9.8$])$ ( $52 \%$ response rate) were received. Of those who responded $56.7 \%$ ( $\mathrm{n}=59$ ) specialized in Periodontics and $43.3 \%(n=45)$ specialized in a variety of other dental disciplines (General Dentistry, Oral Surgery and Implantology). Guided tissue regeneration procedures and the use of enamel matrix derivative were recommended for the reconstruction of bony defects and both subepithelial connective tissue graft and coronally advanced flap with or without enamel matrix derivative were the most popular choices for root coverage. Smoking was considered a contraindication by most of the participants and conflicting responses were given regarding the use of antibiotics as part of the post-operative care following regenerative procedures.

Conclusions: The participants incorporated both traditional and "novel" techniques and products in reconstructive procedures and appeared to be up to date with the evidence from the dental literature. However, it was evident that there was confusion regarding the role of antibiotics in regenerative procedures.

\section{Introduction}

Reconstructive periodontal surgery has been one of the most dynamic and innovative therapeutic procedures in periodontology over the last 30-40 years. However, the goal of regeneration of the periodontal supporting tissues remains both unpredictable and challenging to the clinician [1,2]. Previously published cross-sectional surveys have reported on the management of regenerative procedures and techniques such as the regeneration of intrabony defects and the coverage of exposed root surfaces [1-4] and several investigators have indicated that there are numerous factors that need to be accounted for and modified before undertaking any surgical procedure of this manner [2-6]. Several reviews have previously established the use of Guided Tissue Regeneration (GTR) procedures for the reconstruction of intrabony and interradicular defects [5-10]. More recently with the advent of tissue engineering in Dentistry and the development of novel biomaterials such as enamel matrix derivative (EMD) in combination with surgical procedures such as GTR have been utilised in general and specialized dental practices [1-2,5-8]. The type of surgical procedure including the flap design and the choice of whether to include regenerative materials or not, is important to achieve complete resolution of both the osseous and soft tissue defect [1]. There have been a number of regenerative materials and surgical techniques such as the Coronally Advanced Flap (CAF) with or without use of Sub-Epithelial Connective Tissue Graft (SCTG), enamel matrix derivative (EMD), as well as the Free Gingival Graft (FGG) procedure which have also been recommended for root 
coverage [11-15]. Several studies have previously sought to evaluate whether the outcomes from clinical research in specialized and hospital-based practices has been translated into mainstream dental practices and whether the clinicians were conversant with the current recommendations and familiar with utilising the new regeneration techniques. The purpose of the present questionnaire-based study was to evaluate the knowledge and preferences of a selected group of Greek dentists in the treatment of a variety of common periodontal defects such as gingival recession, intrabony and furcation defects and to compare the results with corresponding findings from two previous studies using a similar questionnaire in two different countries.

\section{Materials and Methods}

The questionnaire was used in previous studies [1,2] and translated into Greek by native speaking Greek Dentists (DC, DS) and retranslated back into English to check for clarification of the text. The design of this study was previously assessed by the Queen Mary University of London Research Ethics Committee, London, UK (Reference: QMREC1343b) Two hundred questionnaires were prepared and distributed by two of the authors (AV, GAM) at several venues as follows: 1) the School of Dentistry of Aristotle University Thessaloniki, Greece, 2) private clinics in Thessaloniki and 3) a national periodontology conference. The participants were given one month to complete and return the questionnaires to the School of Dentistry in Thessaloniki.

The questionnaire consisted of 21 open and closed questions, divided in two main sections. The questions' format was multiplechoice or open-ended or dichotomous in nature. The first section consisted of six questions and was designed to collect demographic data of the sample such as age, gender, specialty (periodontics, general dentistry, implantology, or other) as well as their year of graduation. To estimate the interest in periodontal regenerative procedures of the participants, they were asked to mark a line on a numerical scale from 1 (no interest) to 10 (high interest) based on the number of subscriptions to periodontal journals as well as the estimated number of periodontal regenerative procedures performed annually. The second section of the questionnaire, consisting of 15 questions, included general questions regarding periodontal regeneration, the site-specific factors that should be considered during the pre- and post-surgical assessment and the type of regenerative materials used in the procedure (Q. 5-6). The second section also included a set of questions about the management of four selected clinical case scenarios with labial marginal tissue recession of different stages (Miller class I-IV) [16] together with the relevant clinical photographs in colour and simplified line diagrams depicting the clinical situation. The participants were asked to choose between the following clinical options (Q. 7) and procedures (Q. 8-12): (1) CAF with or without EMD, (2) SCTG, (3) FGG, (4) laterally positioned flap (LPF), (5) double papilla flap (DPF), (6) GTR, and/or (7) other treatment. Following this section four further clinical photographs in colour with accompanying simplified diagrams of three-, two-, onewall intrabony defects and class II furcation defects required from the participants to provide a response about the potential management of the specific clinical scenario. (Q. 13-16). Several treatment choices were provided for each of the clinical scenarios such as: (1) open flap debridement alone (OFD), (2) resective surgery, (3) GTR, (4) bone graft with or without barrier membrane, (5) EMD with or without bone fillers, and/or (6) other options A final set of questions asked about the frequency of EMD use per month and whether the participants used any special flap designs during periodontal regeneration procedures such as a papilla preservation or a coronally advanced flap procedure [CAF] (Q 17-18). Last but not least, questions relating to the exclusion of smokers from regenerative procedures and whether systemic antimicrobials should be prescribed as part of the postoperative care as well as an estimation of patients' acceptance of using animal derived regenerative materials in regenerative procedures were also included (Q. 19-21].

\section{Results}

104 questionnaires (67 Male; 37 female participants; mean age $43.2 \pm 9.8$ years) were returned (52\% response rate) to the School of Dentistry in Thessaloniki. The mean years after graduation from University was $19.3 \pm 10.2$ for the participants (range 1-41 years). Of those who responded 56.7\% ( $\mathrm{n}=59)$ specialized in Periodontics and the rest of the participants $(43.3 \% ; n=45)$ specialized in a variety of other dental disciplines (General Dentistry, Oral Surgery and Implantology). Data management and analysis of the returned responses was performed using both Microsoft Excel 2007 (Microsoft Corporation, Reading, UK) and SPSS ${ }^{\circledR}$ version 22.0 software (IBM United Kingdom Ltd, Portsmouth, UK) and presented in the form of frequency tables, charts, and figures. $71.2 \%(n=74)$ of the participants responded that they have a subscription in at least one periodontal journal whereas $28.8 \%(n=30)$ reported not having any. $94.5 \%(n=69)$ of those who subscribed to periodontal journals answered that they had up to four subscriptions, whereas $(29.8 \%$ of the participants declined to give an answer). When asked to express their interest in periodontal regeneration procedures $76 \%(\mathrm{n}=79)$ recorded a Visual Analogue Scale score of 7 and above, 19.2\% $(n=20)$ a score of 4-6 and $4.8 \%(\mathrm{n}=5)$ indicated a VAS score between 1-3 (Q. 5). When asked to estimate the number of regenerative procedures (\%) that they had performed in one year (Q.6) $87.5 \%(n=91)$ estimated that up to $30 \%$ of the surgeries performed in their clinical practice annually were regenerative in nature (mean percentage $20.5 \% \pm 17.1 \%$ ).

The main clinical parameters that were evaluated prior to and following a regenerative procedure are shown in Figure 1.

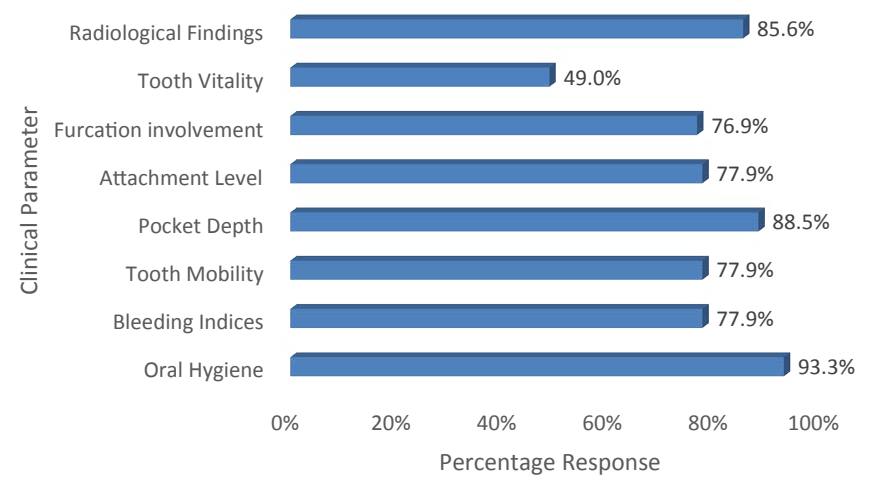

Figure 1: Parameters considered prior to and following a regenerative procedure (Q.7). 
In response to the techniques and materials commonly used in regenerative procedures (Q.8) the most popular choices were 1) EMD (74\%; $\mathrm{n}=77), 2)$ GTR with a resorbable barrier membrane $(57.7 \%$; $\mathrm{n}=60$ ), 3) Allogenic graft (with or without a barrier membrane) $(57.7 \% ; \mathrm{n}=60)$ and 4$)$ Xenogenic graft (with or without a barrier membrane) (51\%: $\mathrm{n}=53)$ (Figure 2).

Q. 9-12 required the participants to indicate their preferences for treatment of four clinical scenarios corresponding to each of the four categories of the Miller Classification for marginal recession defects.

The responses for treating a Miller Class I defect were as follow: 1$)$ CTG (69.2\%; n=72), 2) CRF (42.3\%; n=44), 3) CRF with EMD (28.8\%; $\mathrm{n}=30$ ) and 4 ) LSF (13.5\%; $\mathrm{n}=14$ ) (Figure 3a). Of the participants who chose "other" as a response, the double papilla flap $(11.5 \% ; n=12)$ and free gingival graft (7.7\%: $\mathrm{n}=8)$ were more frequently suggested. The responses for the treatment of a Miller Class II marginal defect were: 1) Connective Tissue Graft (68.3\%; $\mathrm{n}=71), 2)$ CRF (19.2\%; $\mathrm{n}=20), 3)$ CRF with $\operatorname{EMD}(19.2 \%$; $=20), 4)$ FGG (15.4\%; $n=16)$ and 5) LSF (14.4\%; $n=15)$ (Figure $3 b)$. Of the other responses a CRP/CTG combination $(30 \% ; n=3)$ and a mucogingival graft $((20 \% ; n=2)$ were suggested as alternative options. The responses for the treatment of a Miller Class III marginal defect were: 1) Free Gingival Graft (26.8\%; $\mathrm{n}=28), 2)$ GTR (17.3\%; $\mathrm{n}=18), 3)$ CTG (5.8\%; $\mathrm{n}=6)$ and 4) 'Other' $(51.9 \% ; n=54)$ Figure 3c). Of the 19 'Other' responses, 36.8\% ( $n=7)$ of the participants administered no treatment, $15.8 \%(n=3)$ suggested a mucogingival graft and $10.5 \%(\mathrm{n}=2)$ suggested a subepithelial graft with a tunnelling technique. The responses for the treatment of a Miller Class IV marginal defect were as follows: 1) Free Gingival Graft (26.8\%; n=28), 2) GTR (17.3\%;n=18), 3) CTG (5.8\%;n=6) and 4) 'Other' (51.9\%; $\mathrm{n}=54$ ) (Figure 3d). Of the 'Other' responses, 53.7\% $(n=29)$ of the participants offered no treatment, 7.4\% $(n=4)$ suggested extraction, $5.6 \%(\mathrm{n}=3)$ offered non specified conservative treatment and 4$) 5.6 \%(n=3)$ suggested a mucogingival graft.

The preferences of the participants regarding various surgical options available for the treatment of intrabony defects namely: (a) 3-wall defect; (b) 2-wall defect; and (c) 1-wall defect were addressed in Q. 13-15. The main preferences for treating a 3-wall defect were: 1) use of a bone filler (45.2\%: $n=47), 2$ ) EMD (43.5\%: $n=45)$, 3) GTR with a resorbable membrane (40.4\%: $\mathrm{n}=42$ ) and 4$)$ EMD with a bone filler (29.8\%: $\mathrm{n}=31$ ) (Figure $4 \mathrm{a}$ )

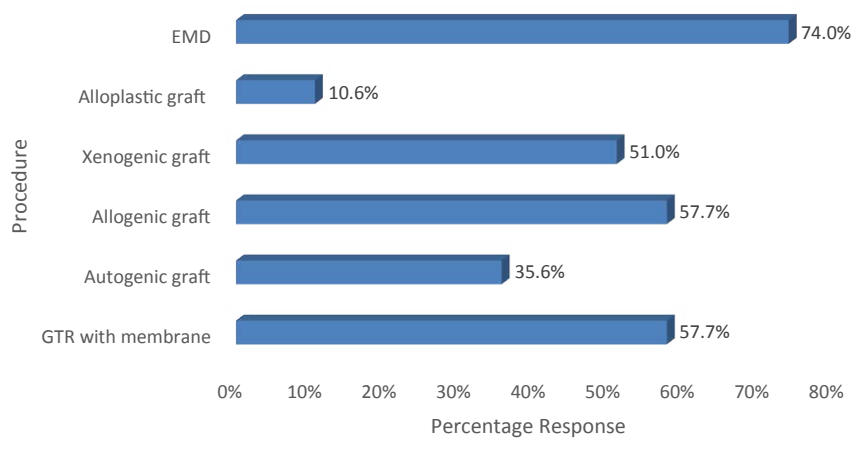

Figure 2: Techniques and materials used in regenerative procedures.
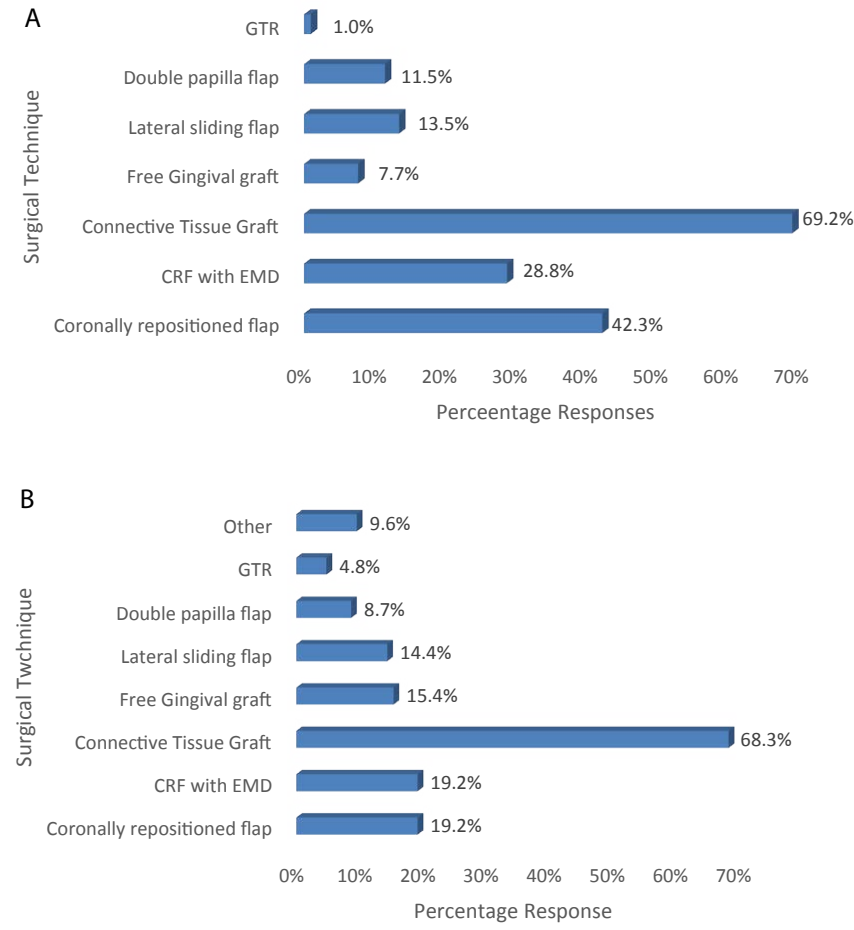

C
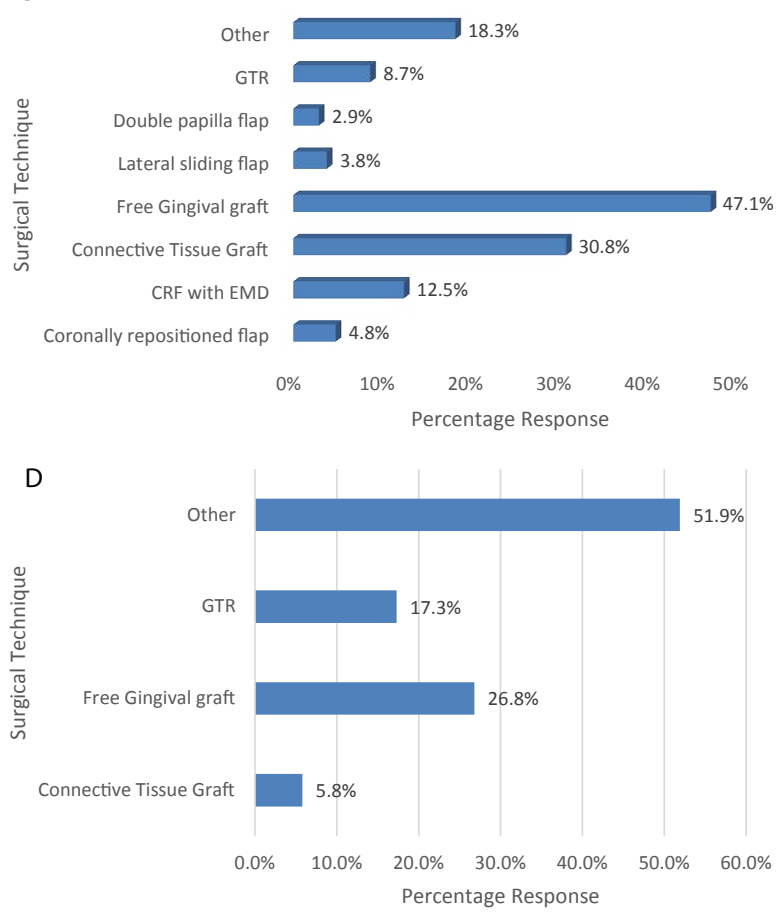

Figure 3a-3d: The preferences of the participants regarding the various treatment options available for the different Miller Classification marginal recession defects (a) Miller Class I; (b) Miller Class II; (c) Miller Class III; and (d) Miller Class IV.

The main preferences for treating a 2-wall defect were: 1) use of a bone filler (51.9\%: $n=54), 2$ ) EMD with a bone filler (34.6\%: $n=36$ ), 3) Open flap debridement only (27.9\%: $\mathrm{n}=29)$ and 4) GTR with a resorbable membrane (25\%: $\mathrm{n}=24$ ) (Figure $4 \mathrm{~b}$ ).

The main preferences for treating a 1-wall defect were: 1) Open flap debridement alone (39.4\%: $\mathrm{n}=41), 2)$ using a bone filler (35.6\%: 
A

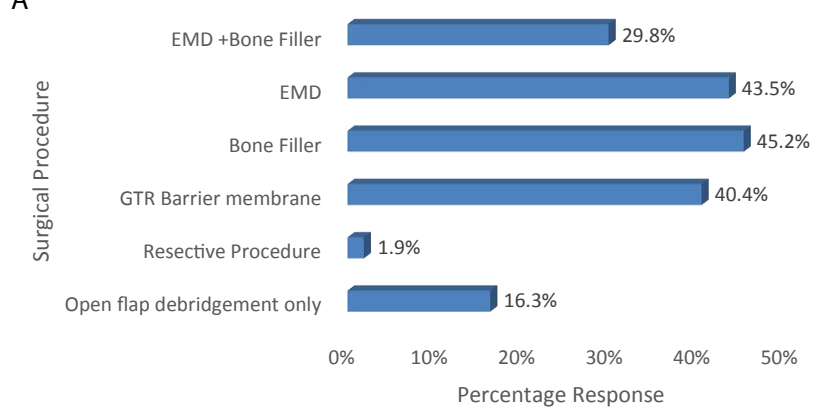

B
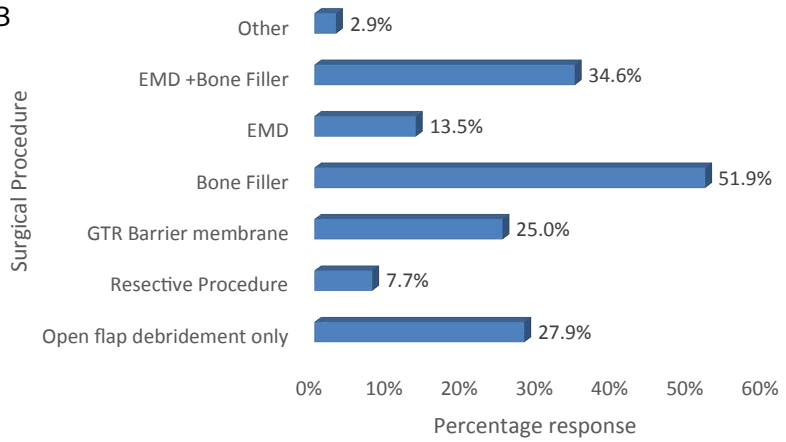

C

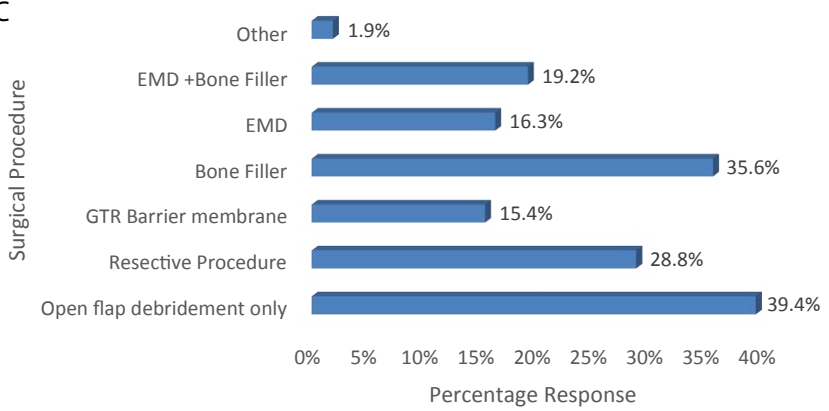

Figure 4a-4c: The preferences of the participants in relation to the various surgical options available for the treatment of intrabony defects namely: (a) 3-wall defect; (b) 2-wall defect; and (c) 1-wall defect.

$\mathrm{n}=37), 3$ ) Resective procedure (28.8\%: $\mathrm{n}=30$ ) and 4) EMD with a bone filler (19.2\%: $\mathrm{n}=20)$ (Figure $4 \mathrm{c}$ ).

The main preferences for treating a Class II furcation defect (Q. 16) were as follows: 1) GTR with a barrier membrane (39.4\%; $n=41$ ), 2) Open flap debridement alone (34.6\%: $n=36), 3$ ) use of a bone filler (29.8\%: $\mathrm{n}=31$ ) and 4) $\operatorname{EMD~(26.9\% :~} \mathrm{n}=28$ ) (Figure 5).

92.3\% ( $n=96)$ of the participants indicated that they used EMD in regenerative procedures (Q. 17). When asked how often was EMD used in regenerative procedures within a month, 58.3\% $(n=60)$ of the participants indicated that they applied the product 1-3 times per month. Of the other responses $14.6 \%(\mathrm{n}=14)$ applied EMD 4-6 times within a month, a $6.8 \%(n=7) 7-9$ times a month. and a $5 \%(n=5)$ of the participants indicated that they never applied EMD during regenerative procedures (Figure 6).

The most popular flap design incorporating a minimally invasive surgical approach (Q. 18) included 1) a papilla preservation technique (38.5\%; $\mathrm{n}=40)$ and 2 ) MIST (30.8\%: $\mathrm{n}=32$ ) (Figure 7).

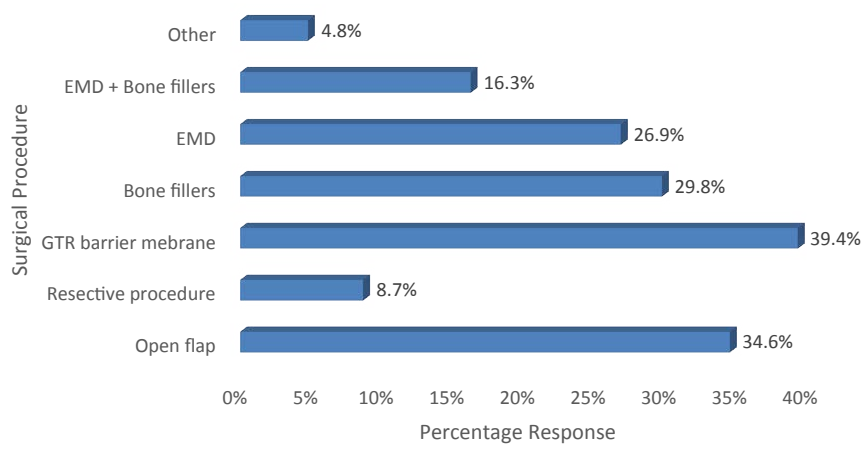

Figure 5: The main preferences for treating a Class II furcation defect.

\section{Monthly application of EMD}

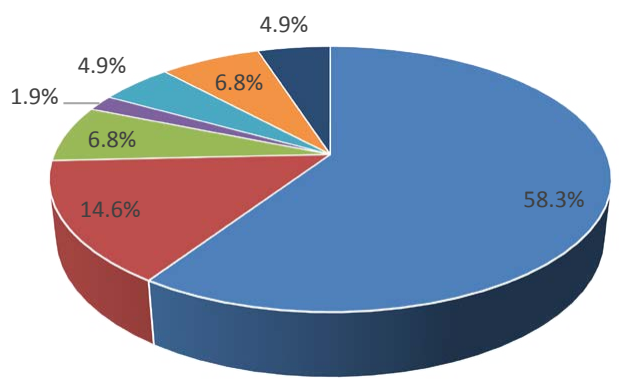

- 1-3 times - 4-6 times - 7-9 times = 10-13 times - Rarely = Other - Never

Figure 6: Estimated monthly application of EMD in regenerative procedures.

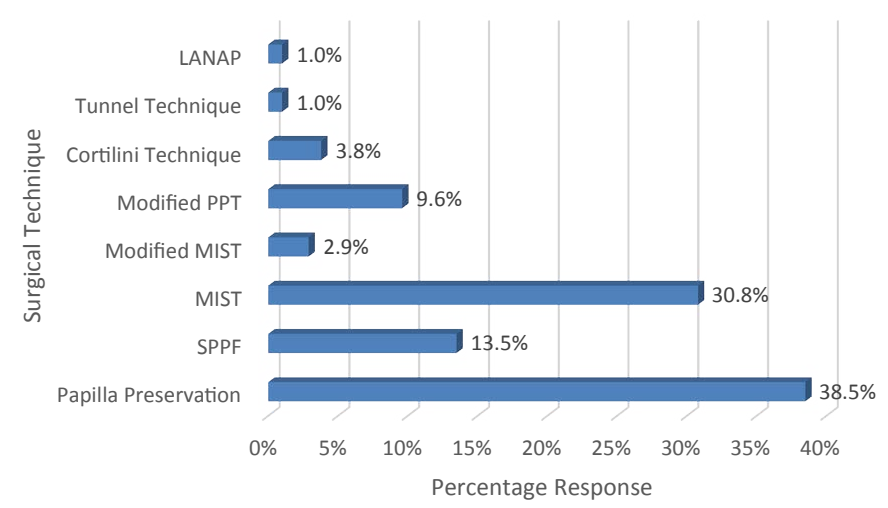

Figure 7: Choice of a specific flap design incorporating a minimally invasive surgical approach.

$70.2 \%(n=73)$ of the participants responded that they usually exclude smokers from regenerative procedures whereas $29.8 \%(n=31)$ indicated that they would attempt a periodontal regeneration surgery to smokers (Q. 19). The main reasons for the exclusion of smokers were compromised host response, impaired wound healing, risk of membrane exposure and a low success rate.

$88.2 \%(n=90)$ of the participants stated that they would prescribe antibiotics (e.g., Amoxicillin and Metronidazole) after a regenerative procedure, but $11.8 \%(\mathrm{n}=12)$ indicated that they would not (Q. 20). Of those participants who would prescribe antibiotics $46.1 \%(n=47)$ indicated that they would do so for at least 9 out of 10 of their patients (Figure 8).

The main antibiotics prescribed after a regenerative procedure (Q. 20) were: 1) Amoxicillin (54.8\%; $\mathrm{n}=57), 2$ ) Amoxicillin and 


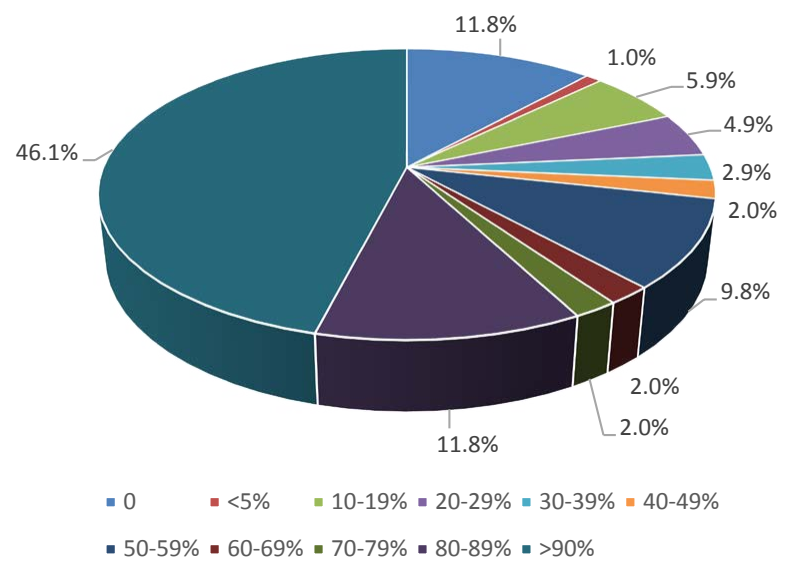

Figure 8: Estimated percentage of patients receiving antibiotics after regeneration procedures.
Clavulanic acid (35.6\%: $\mathrm{n}=37), 3)$ Metronidazole (16.3\%: $\mathrm{n}=17)$ and 4) Clindamycin (15.4\%: $n=16)$.

When asked whether any of their patients had refused to have an animal derived product placed in situ as part of a regenerative procedure, $84.6 \%(\mathrm{n}=88)$ of the participants gave a negative answer (Q. 21), whereas of those participants who indicated that their patients may refuse to receive one of these products, $(8.7 \% ; n=9)$, although, $\leq$ $5 \%$ of the patients would actually refuse an animal derived product as part of a regenerative procedure.

A comparison of the results from the present study together with the previous outcomes from the UK and Kuwaiti studies are shown in Table 1.

Table 1: Comparison of studies in the UK, Kuwait and Greece.

\begin{tabular}{|c|c|c|c|}
\hline Question & Siaili et al. (UK) & Abdulwahab et al. (Kuwait) & Violesti et al. (Greece) \\
\hline Q. 1-2 Demographics (Age: Gender) & $\begin{array}{l}141 \text { participants (M:84: F: } 51 \text { mean: } 44 \pm \\
1.05 \text { years) Response rate: } 38.5 \%\end{array}$ & $\begin{array}{l}129 \text { participants (M 90: F 39; mean age: } 35.7 \pm 7.2 \\
\text { years). Response rate } 86 \% \text {. }\end{array}$ & $\begin{array}{l}104 \text { participants (M 67: F } 37 \text {; mean age } 43.2 \pm 9.8 \\
\text { years). Response rate } 52 \% \text {. }\end{array}$ \\
\hline Q. 3 Professional Status & $\begin{array}{l}65.5 \%(\mathrm{n}=91) \text { specialized in Periodontics } \\
\text { and } 35.5 \%(\mathrm{n}=50) \text { were General Dental } \\
\text { Practitioners with a special interest in } \\
\text { Periodontics. }\end{array}$ & $\begin{array}{l}55.8 \%(\mathrm{n}=72) \text { were General Dental Practitioners, } \\
26 \%(\mathrm{n}=34) \text { specialised in Periodontics. Other } \\
\text { disciplines included Oral Surgery, Orthodontics } \\
\text { Implantology and Prosthodontics. }\end{array}$ & $\begin{array}{l}56.7 \%(\mathrm{n}=59) \text { specialized in Periodontics, } 43.3 \% \\
(\mathrm{n}=45) \text { specialized in a variety of dental disciplines } \\
\text { including Periodontics, General Dentistry, Oral } \\
\text { Surgery and Implantology) }\end{array}$ \\
\hline Q. 4 Years from Graduation & $20 \pm 1.04$ years (range $2-50$ years) & $9.8 \pm 7.0$ years (range $0-33$ years) & $19.3 \pm 10.2$ years (range $1-41$ years) \\
\hline Q. 5a-b Journal Subscription & $\begin{array}{l}68.1 \%(\mathrm{n}=96) \text { subscribed to one or more } \\
\text { journals }\end{array}$ & $30 \%(n=39)$ subscribed to one or more journals & $71.2 \%(n=74)$ subscribed to one or more journals \\
\hline $\begin{array}{l}\text { Q. 5c Interest in Periodontal } \\
\text { Regenerative procedures }\end{array}$ & Mean VAS $7.57 \pm 0.2($ High $)$ & Mean VAS $6.5 \pm 2.3$ (Moderate) & Mean VAS $7.79 \pm 2.2($ High $)$ \\
\hline $\begin{array}{l}\text { Q. } 6 \text { Estimation of the number of } \\
\text { Regenerative procedures }\end{array}$ & Mean percentage $14 \% \pm 1.96 \%$ & Mean percentage $27.5 \% \pm 25.5 \%$ & Mean percentage $20.5 \% \pm 17.1 \%$ \\
\hline $\begin{array}{l}\text { Q. } 7 \text { Parameters to be considered } \\
\text { prior to and following a regenerative } \\
\text { procedure }\end{array}$ & \begin{tabular}{|l|}
$\begin{array}{l}\text { Oral hygiene, pocket depth } \\
\text { measurement, radiographic presentation } \\
\text { and, CAL }\end{array}$ \\
\end{tabular} & $\begin{array}{l}\text { Oral hygiene, tooth mobility, probing depth } \\
\text { measurements and radiographic presentation }\end{array}$ & $\begin{array}{l}\text { Oral hygiene, pocket depth measurement, } \\
\text { radiographic presentation and, CAL }\end{array}$ \\
\hline $\begin{array}{l}\text { Q. } 8 \text { Techniques and materials used in } \\
\text { regenerative procedures }\end{array}$ & $\begin{array}{l}\text { 1) EMD, 2) GTR with a resorbable } \\
\text { (absorbable) membrane }\end{array}$ & $\begin{array}{l}\text { 1) GTR, 2) allogenic graft (with or without a } \\
\text { barrier membrane), 3) alloplastic grafts (with or } \\
\text { without a barrier membrane) and 4) EMD }\end{array}$ & $\begin{array}{l}\text { 1) EMD, 2) GTR with a resorbable barrier membrane), } \\
\text { 3) Allogenic graft (with or without a barrier } \\
\text { membrane) and 4) Xenogenic graft (with or without a } \\
\text { barrier membrane) }\end{array}$ \\
\hline $\begin{array}{l}\text { Q. } 9 \text { The preferences of the participants } \\
\text { regarding the various treatment } \\
\text { options available of a Miller Class I } \\
\text { marginal defect }\end{array}$ & $\begin{array}{l}\text { 1) SCTG, 2) CAF, 3) FGG and 4) CAF } \\
\text { with EMD }\end{array}$ & 1) CRF, 2) CTG, 3) FGG and 4) CRF with EMD & 1) CTG, 2) CRF 3) CRF with EMD and 4) LSF \\
\hline $\begin{array}{l}\text { Q.10 The preferences of the } \\
\text { participants regarding the various } \\
\text { treatment options available of a Miller } \\
\text { Class II marginal defect }\end{array}$ & $\begin{array}{l}\text { 1) SCTG, 2) FGG, 3) CAF with EMD } \\
\text { and 4) CAF }\end{array}$ & 1) CTG, 2) CRF, 3) GTR and 4) CRF with EMD & 1) CTG 2) CRF, 3) CRF with EMD and 4) FGG \\
\hline $\begin{array}{l}\text { Q.11 The preferences of the } \\
\text { participants regarding the various } \\
\text { treatment options available of a Miller } \\
\text { Class III marginal defect }\end{array}$ & $\begin{array}{l}\text { 1) SCTG, 2) FGG and 3) "Other" (e.g., } \\
\text { non-surgical treatment) }\end{array}$ & $\begin{array}{l}\text { 1) GTR with a resorbable barrier membrane 2) } \\
\text { FGG, 3) CTG and 4) LSF }\end{array}$ & $\begin{array}{l}\text { 1) FGG, 2) GTR, 3) CTG and 4) 'Other' (no treatment, } \\
\text { a mucogingival graft and a subepithelial graft with } \\
\text { tunnelling) }\end{array}$ \\
\hline $\begin{array}{l}\text { Q.12 The preferences of the } \\
\text { participants regarding the various } \\
\text { treatment options available of a Miller } \\
\text { Class IV marginal defect }\end{array}$ & $\begin{array}{l}\text { 1) FGG and 2) GTR procedures were } \\
\text { indicated although 3) other treatment } \\
\text { options such as 'nonsurgical treatment' } \\
\text { and extraction were preferable } \\
\end{array}$ & $\begin{array}{l}\text { GTR with a resorbable barrier membrane and } \\
\text { CTG were recommended although 'Extraction' was } \\
\text { the preferred option }\end{array}$ & $\begin{array}{l}\text { 1) FGG, 2) GTR, 3) CTG 4) other options preferred } \\
\text { such as no treatment, extraction, and non-specified } \\
\text { conservative treatment or a mucogingival graft. }\end{array}$ \\
\hline $\begin{array}{l}\text { Q. } 13 \text { The preferences of the } \\
\text { participants in relation to the various } \\
\text { surgical options available for the } \\
\text { treatment of a 3-wall infrabony defect }\end{array}$ & $\begin{array}{l}\text { 1) EMD without and with bone grafts } \\
\text { (filler) and 2) using bone grafts (filler) } \\
\text { with or without the use of barrier } \\
\text { membranes }\end{array}$ & $\begin{array}{l}\text { 1) GTR with a resorbable barrier membrane, 2) } \\
\text { bone grafts (filler), 3) OFD and 4) EMD combined } \\
\text { with bone grafts }\end{array}$ & $\begin{array}{l}\text { 1) using a bone filler, 2) EMD, 3) GTR with a } \\
\text { resorbable membrane, and 4) EMD with a bone filler }\end{array}$ \\
\hline $\begin{array}{l}\text { Q. } 14 \text { The preferences of the } \\
\text { participants in relation to the various } \\
\text { surgical options available for the } \\
\text { treatment of a 2-wall infrabony defect }\end{array}$ & $\begin{array}{l}\text { 1) EMD combined with bone grafts, } \\
\text { 2) bone grafts (filler) with or without } \\
\text { barrier membranes, 3) GTR with } \\
\text { resorbable membranes and (4) EMD }\end{array}$ & $\begin{array}{l}\text { 1) GTR with a resorbable barrier membrane, 2) } \\
\text { bone grafts (filler), 3) combined with bone grafts } \\
\text { and 4) OFD }\end{array}$ & $\begin{array}{l}\text { 1) using a bone filler, 2) EMD with a bone filler, 3) } \\
\text { OFD and 4) GTR with a resorbable membrane }\end{array}$ \\
\hline $\begin{array}{l}\text { Q. } 15 \text { The preferences of the } \\
\text { participants in relation to the various } \\
\text { surgical options available for the } \\
\text { treatment of a 1-wall infrabony defect }\end{array}$ & 1) Resective surgery and 2) OFD & $\begin{array}{l}\text { 1) Resective surgery, 2) OFD, 3) Bone graft and 4) } \\
\text { GTR with the use of a resorbable barrier }\end{array}$ & $\begin{array}{l}\text { 1) OFD 2) using a bone filler, 3) Resective procedure } \\
\text { and 4) EMD with a bone filler }\end{array}$ \\
\hline
\end{tabular}




\begin{tabular}{|c|c|c|c|}
\hline $\begin{array}{l}\text { Q. } 16 \text { The main preferences for } \\
\text { treating a Class II furcation defect }\end{array}$ & $\begin{array}{l}\text { 1) EMD, 2) GTR with the use of } \\
\text { resorbable barrier membranes 3) OFD } \\
\text { 4) EMD and bone grafts 5) resective } \\
\text { surgery And 6) bone grafts with or } \\
\text { without barrier membranes }\end{array}$ & $\begin{array}{l}\text { 1) GTR with a resorbable barrier, 2) OFD and bone } \\
\text { graft. EMD was the least preferred option for the } \\
\text { management of a Class II furcation defect }\end{array}$ & $\begin{array}{l}\text { 1) GTR with a barrier membrane 2) Open flap } \\
\text { debridement only, 3) using a bone filler, and 4) EMD }\end{array}$ \\
\hline $\begin{array}{l}\text { Q. } 17 \text { Estimated monthly application } \\
\text { of EMD in regenerative procedures }\end{array}$ & $\begin{array}{l}\text { The main response was one to three } \\
\text { times per month }\end{array}$ & $\begin{array}{l}\text { The main response was one to three times per } \\
\text { month }\end{array}$ & The main response was one to three times per month \\
\hline $\begin{array}{l}\text { Q. } 18 \text { Choice of a specific flap design } \\
\text { incorporating a minimally invasive } \\
\text { surgical approach }\end{array}$ & $\begin{array}{l}\text { 1) The papilla preservation flap and 2) } \\
\text { coronally advanced flap }\end{array}$ & $\begin{array}{l}\text { 1) Papilla preservation 2) coronally displaced } \\
\text { (advanced) flap }\end{array}$ & $\begin{array}{l}\text { 1) a papilla preservation technique and 2) MIST } \\
\text { procedures }\end{array}$ \\
\hline $\begin{array}{l}\text { Q. } 19 \text { Would Smokers be excluded } \\
\text { from regenerative procedures }\end{array}$ & \begin{tabular}{|l|} 
Smoking was considered a \\
contraindication for regenerative \\
procedures by most of the participants. \\
Vasoconstriction, impaired \\
postoperative healing, and compromised \\
outcomes were reasons why Smokers \\
should be excluded from these \\
procedures.
\end{tabular} & $\begin{array}{l}\text { Smoking was not considered a contraindication for } \\
\text { regenerative procedures by most of the participants } \\
\text { of those participants who would exclude Smokers } \\
\text { factors such as impaired healing, poor prognosis, } \\
\text { vasoconstriction and, treatment results in failure } \\
\text { (low success rate) }\end{array}$ & $\begin{array}{l}\text { Smoking was considered a contraindication for } \\
\text { regenerative procedures by most of the participants. } \\
\text { The main reasons for exclusion included a } \\
\text { compromised host response, wound healing, risk of } \\
\text { membrane exposed and a low success rate. }\end{array}$ \\
\hline $\begin{array}{l}\text { Q. } 20 \text { Prescription of antibiotics } \\
\text { following regenerative procedures }\end{array}$ & \begin{tabular}{|l|} 
Most of the participants reported that \\
they would prescribe antibiotics for their \\
patients with $35 \%$ indicating that they \\
would not prescribe antibiotics
\end{tabular} & $\begin{array}{l}\text { Most of the participants reported that they would } \\
\text { prescribe antibiotics for their patients with } 9.6 \% \\
\text { indicating that they would not prescribe antibiotics }\end{array}$ & $\begin{array}{l}\text { Most of the participants reported that they would } \\
\text { prescribe antibiotics for their patients with } 11.8 \% \\
\text { indicating that they would not prescribe antibiotics }\end{array}$ \\
\hline $\begin{array}{l}\text { Q. } 20 \text { Choice of Antibiotic prescribed } \\
\text { to patients }\end{array}$ & \begin{tabular}{|l|} 
1) Amoxicillin, 2) Combination of \\
Amoxicillin and 3) Metronidazole and \\
4) Doxycycline Metronidazole,
\end{tabular} & $\begin{array}{l}\text { 1) Combination of Amoxicillin and Metronidazole, } \\
\text { 2) Augmentin, 3) Amoxicillin and 4) Clindamycin }\end{array}$ & $\begin{array}{l}\text { 1) Amoxicillin, 2) Amoxicillin and Clavulanic acid), 3) } \\
\text { Metronidazole and 4) Clindamycin }\end{array}$ \\
\hline $\begin{array}{l}\text { Q. } 21 \text { What } \% \text { of your patients } \\
\text { undergoing a regenerative procedure } \\
\text { would reject an animal derived } \\
\text { material }\end{array}$ & \begin{tabular}{|l|} 
ariable response with at least one-third \\
of the participants indicating that their \\
patients would not reject an animal \\
derived material. Of those participants \\
who indicated that their patients may \\
refuse to have one of these products $<5 \%$ \\
of their patients would do so
\end{tabular} & $\begin{array}{l}\text { Most of the participants reported that } \\
\text { their patients would reject an animal-derived } \\
\text { material. According to the participants' responses, } \\
\text { at least } 30 \% \text { of their patients would reject the } \\
\text { product. }\end{array}$ & $\begin{array}{l}\text { Most of the participants indicated that none of their } \\
\text { patients would reject an animal derived material. Of } \\
\text { those participants who indicated that their patients } \\
\text { may refuse to have one of these products }<5 \% \text { of their } \\
\text { patients would do so. }\end{array}$ \\
\hline
\end{tabular}

Key: M: Male; CAF: Coronally Advanced Flap; F: Female; FGG: Free Gingival Graft; VAS: Visual Analogue Scale; CRF: Coronally Repositioned Flap; EMD: Enamel Matrix Derivative; LSF: Laterally Sliding Flap; GTR: Guided Tissue Regeneration; OFD: Open Flap Debridement; SCTG: Subepithelial Connective Tissue Graft.

\section{Discussion}

The aim of the present study was to assess the awareness and preferences of a selected group of Greek clinicians and to compare the outcomes with two previous cross-sectional questionnaire studies in the UK and Kuwait [1,2]. The response rates from the three studies were at variance with each other (38.5\% to $86 \%)$ differing also from the response rate of the present study, which was $52 \%$. When comparing the age and experience of the participating dentists with the two previous studies [1,2], the age and experience of the Greek dentists were comparable with the UK study [1] although the dentists in the Kuwait study [2] were on average younger with less clinical experience. The professional status of both the UK based clinicians and those in the present study was similar with $>50 \%$ of the participants being specialized in Periodontics as compared to the Kuwaiti sample where only $26 \%$ was specialized in Periodontology. This was evident when comparing the interest in performing regenerative procedures. The result of the present study was comparable to the UK based study with both groups expressing a high degree of interest in performing regenerative procedures (Mean VAS $7.79 \pm 2.2$ [Greek]: $7.57 \pm 0.2[\mathrm{UK}])$ whereas the corresponding result from Kuwait was moderate (mean VAS $6.5 \pm 2.3$ ). The mean percentage of periodontal regenerative procedures recorded in the present study (20.5\%) was comparable to the Kuwaiti based group (27.5\%) and remarkably higher comparatively to the one recorded in the UK study (14\%). When considering the clinical parameters taken into account prior to and following a periodontal regeneration procedure, the overall responses from the three studies (oral hygiene, pocket depth measurements, radiographic presentation and CAL) from Greece and the UK were similar although in the Kuwaiti study the assessment of CAL seemed to be underestimated. The assessment of CAL is perhaps one of the most important factors in periodontal regeneration [9] and the apparent underestimation of this factor may be the result of the lack of experience of the younger participants in Kuwait. When considering the type of technique(s) and materials used in regenerative procedures both the UK and Greek group indicated that they prefer 1) EMD and 2) GTR with a resorbable membrane. On the other hand, the Kuwaiti group indicated that although they widely choose a GTR procedure as well, they prefer to combine this technique with either allogenic or alloplastic grafts (with or without the use of a membrane). Notably, at the time of conducting the study in Kuwait the use EMD was not as popular as in the UK and Greece.

Comparison of the preferred treatment modalities for the four selected clinical situations based on the Miller Classification [16] (Q. 9-12) evaluated the participants' responses to root coverage procedures in terms of the 'the most predictable' outcome for the clinical cases (Miller Class I \& II defects) as well as the 'least predictable' outcomes based on Miller Class III \& IV recession defects. The most popular technique to treat Miller Class I defects was a CTG procedure in agreement with [1] but not with [2] where the principal choice was a CRF/CAF procedure (Table 1). For the treatment of a Miller Class II defect a CTG procedure was the most popular choice in all three studies in agreement with evidence from the published literature, indicating the superiority of CAF with or without EMD and/or CTG in root coverage procedures [15]. The responses for treating a Miller 
Class III defect were at variance with the other two studies in that the main choice in the present study was for a FGG procedure which was not the first choice in the other two studies [1,2] although it was popular (Table 1). The treatment preferences for managing a Miller Class IV defect were in general agreement with the studies from the UK [1] and Kuwait [2] Although the Kuwaiti study's first preference was a GTR procedure, other options including non-surgical treatment and extractions which was also suggested in all three studies (Table 1).

Responses to Q. 13-15 related to the materials and techniques used in the management of 1,2 or 3-walled intrabony defects indicated that in the management of both the 3- and 2- walled defects there was overall agreement between the three studies with EMD (with/ without a bone filler) being favoured in the present study and the UK study [1]. On the contrary, GTR procedures were favoured in the Kuwaiti study [2] (Table 1). For the treatment of a 1-walled infrabony defect OFD was the first choice in the present study, whereas resective surgery was the preferred choice in the UK and Kuwaiti studies [1,2]. The differences in the use of EMD between the present study and the Kuwaiti study may either have been related to religious issues or the availability of the specified biomaterial. Furthermore, it should be recognised that some of the minimally invasive procedures employed in Specialist and Hospital based practices may not be undertaken in the general practice environment.

The main preferences for treating a Class II furcation defect (Q. $16)$ in the present study were 1) GTR with a barrier membrane (39.4\%; $\mathrm{n}=41)$, 2) Open flap debridement alone (34.6\%: $\mathrm{n}=36), 3)$ use of a bone filler (29.8\%: $\mathrm{n}=31$ ) and 4) EMD (26.9\%: $\mathrm{n}=28$ ) (Figure 6) in agreement with Abdulwahab et al. [2]. The main difference between the UK study and the other two was the preference for EMD $[1,2]$ (Table 1). In response to Q. 17 there was general agreement as far as the estimated monthly EMD application was concerned (Table 1). The main choice of a specific flap design incorporating a minimally invasive surgical approach was the papilla preservation flap (Q. 18) (Table 1). Flap design is of critical importance in regenerative procedures as it facilitates both full surgical site coverage and wound stability during the healing process [11].

When asked whether smoking was a contraindication for regenerative procedures (Q. 19), most of the participants in the present study concurred with those in the UK study [1] that smokers should be excluded. This was in contradistinction to the Kuwaiti study [2] where smokers would not be excluded (Table 1). Evidence from previous studies would suggest that smokers appear to have impaired healing response as well as lower frequencies of complete root coverage compared to non-smokers $[13,16]$.

Most of the participants in all three studies would prescribe antibiotics after a regenerative procedure (Q. 20). The number of dentists who would prescribe antibiotics was higher for both the present and the Kuwaiti study [2] as compared to the results from the UK [1] indicating that a larger number of respondents in the UK study would not prescribe antibiotics after a periodontal regeneration surgery (Table 1). According to Abdulwahab et al. [2] this response from UK dentists may be due to a greater awareness of the current problems with antibiotic resistance due to over-prescription. The choice of a specific antibiotic (Q. 20) in the present study was in general agreement with previous studies $[1,2]$ (Table 1).

The acceptance or rejection of an animal-derived regenerative material as part of the regenerative procedure by the patients $(\mathrm{Q}$. 21) may depend on the cultural or religious beliefs of the patients. For example, most of the participants in the present study would accept this kind of material in agreement with studies $[1,3]$ but in contradiction with [2] where most of the participants would reject this material based on their patients' preferences (Table 1).

The results from the present study appear to validate the questionnaire previously used $[1,2]$ and there was general agreement from the three studies on how practitioners would treat the various clinical scenarios however it was evident that several points of disagreement arose from the results of the two previous studies [1,2] such as whether to exclude smokers prior to a regenerative procedure, post-operative administration of antibiotics following regenerative procedures [2] or the acceptance of animal derived products during these procedures. The results from the present study generally concur with previous European studies, particularly regarding the use of animal derived biomaterials $[1,3]$. The techniques and regenerative materials have changed over the last decade and this may be reflected in the responses acquired by the three studies. This may also suggest that there is a lag period regarding the transfer of information from evidence-based clinical practice to the general practice as well a lack of opportunity or availability to develop clinical skills from hands on clinical training in regenerative procedures.

\section{Conclusion}

The results of the present pilot study would suggest that dentists need to be more informed regarding recent innovations in regenerative procedures and techniques when treating a range of periodontal defects.

\section{Acknowledgements}

The investigators would like to thank all the participants who helped with this study.

\section{Reference}

1. Siaili M, Chatzopoulou D, Gillam DG (2014) Preferences of UK-Based Dentists When Undertaking Root Coverage and Regenerative Procedures: A Pilot Questionnaire Study. Int J Dent 2014: 548519. [crossref]

2. Abdulwahab A, Chatzopoulou D and Gillam DG (2018) A Survey of the Professional Opinions of Dentists in Kuwait in the Use of Periodontal Regenerative Surgical Procedures for the Treatment of Infra Bony and Localized Gingival Defects. J Dent \& Oral Disord 4: 1104.

3. Schroen O, Sahrmann P, Roos M, Attin T, Schmidlin PR (2011) A survey on regenerative surgery performed by Swiss specialists in periodontology with special emphasis on the application of enamel matrix derivatives in infrabony defects. Schweiz Monatsschr Zahnmed 121: 136-142. [crossref]

4. Zaher CA, Hachem J, Puhan MA, Mombelli A (2005) Interest in periodontology and preferences for treatment of localized gingival recessions: a survey among Swiss dentists. Journal of Clinical Periodontology 32: 375-382. [crossref]

5. Needleman I Tucker, R Giedrys-Leeper E, Worthington H (2005) Guided tissue regeneration for periodontal intrabony defects-a Cochrane systematic review. Periodontol 2000 37: 106-123. [crossref]

6. Cortellini P, Tonetti MS (2009) Improved wound stability with a modified minimally invasive surgical technique in the regenerative treatment of isolated interdental intrabony defects. Journal of Clinical Periodontology 36: 157-163. [crossref] 
Violesti A (2020) Perception and Understanding of Greek Dentists on Periodontal Regenerative Procedures: A Questionnaire Based Study

7. Esposito M, Grusovin MG, Papanikolaou N, Coulthard P, Worthington HV (2009) Enamel matrix derivative (Emdogain) for periodontal tissue regeneration in intrabony defects. Eur J Oral Implantol 2: 247-266. [crossref]

8. Trombelli L, Farina R (2008) Clinical outcomes with bioactive agents alone or in combination with grafting or guided tissue regeneration. J Clin Periodontol 35: 117135. [crossref]

9. Caton JG, Greenstein G (1993) Factors related to periodontal regeneration. Periodontol 2000 1: 9-15. [crossref]

10. Cortellini P, Tonetti MS (2005) Clinical performance of a regenerative strategy for intrabony defects: scientific evidence and clinical experience. Journal of Periodontology 76: 341-350. [crossref]

11. Chambrone L, Chambrone D, Pustiglioni FE, Chambrone LA, Lima LA (2008) Can subepithelial connective tissue grafts be considered the gold standard procedure in the treatment of Miller Class I and II recession-type defects? J Dent 36: 659-671. [crossref]
12. Chambrone L, Pannuti CM, Tu Y-K, Chambrone LA (2012) Evidence-based periodontal plastic surgery. II. An individual data meta-analysis for evaluating factors in achieving complete root coverage. J Periodontol 83: 477-490. [crossref]

13. Cheng YF, Chen JW, Lin SJ, Lu HK (2007) Is coronally positioned flap procedure adjunct with enamel matrix derivative or root conditioning a relevant predictor for achieving root coverage? A systemic review. J Periodontal Res 42: 474-485. [crossref]

14. Cairo F, Pagliaro U, Nieri M (2008) Treatment of gingival recession with coronally advanced flap procedures: a systematic review. J Clin Perio 35: 136-162. [crossref]

15. Miller Jr PD (1985) A classification of marginal tissue recession. The International Journal of Periodontics \& Restorative Dentistry 5: 8-13. [crossref]

16. Trombelli L, Scabbia A (1997) Healing response of gingival recession defects following guided tissue regeneration procedures in smokers and non-smokers. J Clin Periodontol 24: 529-533. [crossref] 